\title{
Copper(II)imida-salen complexes encapsulated into NaY zeolite for oxidations reactions
}

\author{
Iwona Kuźniarska-Biernacka $^{*[a]}$, M. Alice Carvalho ${ }^{[a]}$, Soren B. Rasmussen ${ }^{[b, c]}$, \\ Miguel A. Bañares ${ }^{[b]}$, Krzysztof Biernacki ${ }^{[\mathrm{d}]}$, Alexandre L. Magalhães ${ }^{[\mathrm{d}]}$, Anabela \\ G. Rolo ${ }^{[\mathrm{e}]}$, António M. Fonseca ${ }^{[\mathrm{a}]}$, Isabel C. Neves ${ }^{[\mathrm{a}]}$
}

[a] Departamento de Química, Centro de Química, Universidade do Minho, Campus de Gualtar, 4710-057 Braga, Portugal Fax:253604382 E-mail:Iwona@quimica.uminho.pt/

[b] Catalytic Spectroscopy Laboratory, Institute of Catalysis and Petrochemistry, CSIC, E-28049 Madrid, Spain

[c] Centre of Catalytic and Sustainable Chemistry, DTU Chemistry, Technical University of Denmark, DK-2800 Kgs.Lyngby, Denmark

[d] REQUIMTE, Departamento de Química e Bioquímica, Faculdade de Ciências, Universidade do Porto, 4169-007 Porto, Portugal Centro de Física,

[e] Departamento de Física, Universidade do Minho, Campus de Gualtar, 4710-057 Braga, Portugal

Keywords: NaY Zeolite; Copper(II); imida-salen ligand; DFT studies; alcohol oxidations

\begin{tabular}{|c|c|}
\hline $\begin{array}{l}\text { copper(II) complexes wi } \\
\text { gand, } \\
\text { ydroxyphenyl)methylene]ar }\end{array}$ & $\begin{array}{l}\text { catalytic activities of the encapsulated } \\
\text { copper(II) complexes in NaY were } \\
\text { compared with the homogeneous } \\
\text { counterpart. The results show higher or } \\
\text { similar substrate conversion when } \\
\text { compared with the free complex in all the } \\
\text { reactions tested. After their use in catalytic }\end{array}$ \\
\hline
\end{tabular}
complexes were

\section{Introduction}

Phenols are toxic and poorly biodegradable pollutants found in wastewaters from a variety of a industrial activities. The effective removal of phenolic pollutants from wastewater is a challenge of great practical importance and interest. Various methods for treating industrial wastewater containing phenols have been widely reported [1]. Among these, chemical oxidation is economically attractive due to the low consumption of chemicals and the production of intermediate products that are less toxic and more biodegradable. Advanced oxidation processes (AOPs), in which catalytic wet hydrogen peroxide oxidation (CWPO) appears to be economical and also efficient under mild conditions [2,3], are highly interesting. The selective oxidation of alcohols is also one of the most important organic transformations in chemical synthesis. The oxidation of cyclohexanol to cyclohexanone is a significant step in the syntheses of adipic acid and caprolactam of which about 2.5 and 2 billion $\mathrm{kg}$, respectively, are produced annually. These intermediates are important in the manufacture of nylon 6 and nylon 66 and also as plasticizers and food additives [4, 5]. In order to produce less byproducts and develop more environmentally friendly methods to oxidize cyclohexanol, a variety of metal catalysts have been investigated [6] included precious metals [7]. In comparison with these metal/metal oxides, transition metal complexes are much less expensive.

The development of new heterogeneous catalysts has become very important for eco-friendly industrial processes. These materials have been developed with the objective of performing reactions under mild conditions and without producing hazardous wastes. These new catalysts can easily be separated from the reaction media and reused, and they are quite stable when compared with corresponding homogeneous counterparts because catalyst deactivation pathways are hindered by local site isolation of the complexes inside the solid supports $[8,9]$.

To improve the efficiency of these heterogeneous catalysts, the zeolite structure offers an ideal support for the encapsulation of metal complexes [9-14]. Zeolites are solid inorganic crystalline materials comprised of silicon, aluminum and oxygen in a three-dimensional structure with microporous channels and cages on a nano- and subnanomete scale of strictly regular 
dimensions [10]. Therefore only active components with an appropriate size and shape can be incorporated into highly porous zeolites. However their mechanical stability could be advantageous during catalysts recycling and reuse [11, 12]. These catalysts are of interestfor their application in the oxidation of alkanes, alkenes and alcohols [13-15].

In this work we demonstrate the catalytically potential of copper(II) Schiff base complexes encapsulated in NaY zeolite for the oxidation of phenol and cyclohexanol. Schiff bases, especially Salen type are wide known class of ligands [16, 17]. The copper(II) complexes described in this study are based on the new Salen type ligand contain an imidazole bridge (Scheme 1). To the best of our knowledge this is a unique example of the use of this Salen-type ligand.

$$
\text { (n) }
$$

Scheme 1. Molecular structure of $\mathrm{H}_{2}$ imida-salen.

The motivation for the use of this imidazole bridge is its strongly electron-donating nature, which increases the stability of the complex. The presence of this unit may also improve the catalytic activity as it is known that electron-donating substituents in the phenolic units of a Schiff base (Salen, $\mathrm{N}_{2} \mathrm{O}_{2}$ type) increase its catalytic activity especially in the oxidation of organic molecules. The catalytic properties of the $\mathrm{Cu}(\mathrm{II})$ complex are studied under homogeneous and heterogeneous conditions in the presence of tert-butylhydroperoxide $(\mathrm{tBuOOH})$ and hydrogen peroxide $\left(\mathrm{H}_{2} \mathrm{O}_{2}\right)$ as oxygen sources.

\section{Results and Discussion}

\section{Characterization and DFT Studies of Free Complex and the Heterogeneous Catalysts}

The heterogeneous catalysts were obtained by two methods: in situ complex synthesis and the flexible ligand approach (designated methods (A) and (B) respectively), whereas the free metal complex was prepared by the standard method (see Exp. Sect.).

SEM micrographs of $\mathrm{NaY}$ zeolite and the zeolites encapsulating copper(II) imida-salen complex prepared by the two methods are presented in Fig. 1.

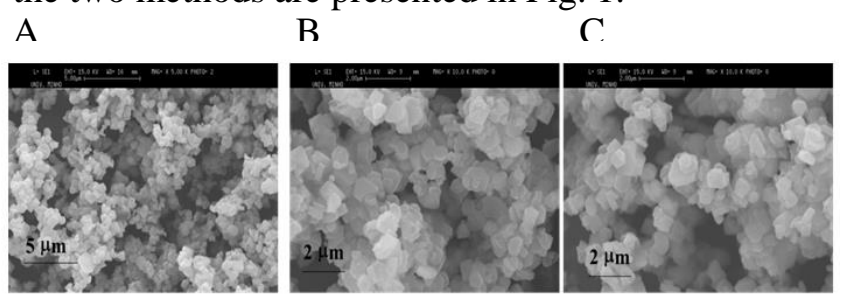

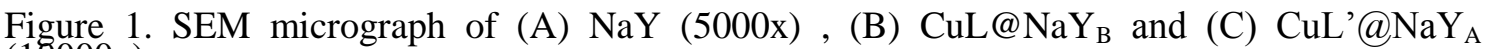
(10000x).

Fig 1(a) represents a morphology typical of the faujasite zeolite. Analysis of the micrographs of $\mathrm{NaY}$ and the heterogeneous catalysts shows that there are no changes in the zeolite morphology or structure upon encapsulation of the complex [13, 18]. It appears from Figure 1 that Soxhlet extraction was efficient and the surface is completely washed out, which indicates the complete removal of uncoordinated ligands and the remaining metal complexes are physically adsorbed on the external surface of zeolite [19]. Furthermore, it is revealed from our SEM analysis that the average particle size before and after encapsulation of the complexes remains unchanged, which also suggests that encapsulation has not led to the destruction of zeolite morphology.

The powder X-ray diffractograms of $\mathrm{NaY}$ and heterogeneous catalysts are shown in Figure 2.

These samples display the expected patterns of hydrated $\mathrm{NaY}$ zeolites, and no diffraction lines assigned to any new phase were detected [20], which indicats that the encapsulated $\mathrm{Cu}$ (II) complexes are highly dispersed in the zeolite structure. Moreover, the zeolite framework has not undergone any significant structural change during metal exchange and encapsulation of the 
complex by the different methods and thus the crystallinity of the zeolite $\mathrm{Y}$ is well preserved, with both heterogenous catalysts showing over $80 \%$ crystallinity

The results of the elemental analysis are summarized in Table 1.

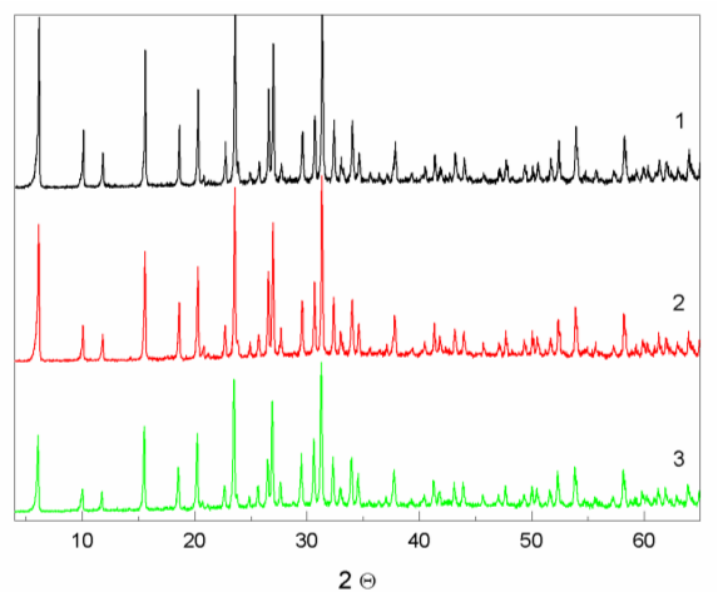

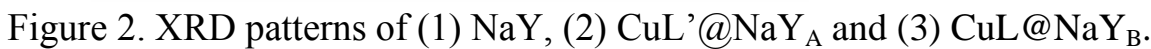

Table 1. Elemental data analysis (\%) of free complex and the heterogeneous catalysts

\begin{tabular}{lccccc}
\hline & \multicolumn{5}{c}{ Elemental analysis } \\
\cline { 2 - 6 } & $\mathrm{Cu}^{\mathrm{a}}$ & $\mathrm{C}^{\mathrm{a}}$ & $\mathrm{N}^{\mathrm{a}}$ & $\mathrm{C} / \mathrm{N}$ & $\mathrm{Cu} / \mathrm{N}$ \\
\hline$[\mathrm{Cu}($ imida-salen $)]$ & $11.43^{\mathrm{b}}$ & 46.99 & 15.25 & 3.08 & 0.75 \\
$\mathrm{CuL} @ \mathrm{NaY}_{\mathrm{A}}$ & 0.09 & 0.46 & 0.05 & 9.20 & 1.80 \\
$\mathrm{CuL}_{\mathrm{NaY}}$ & 0.13 & 0.24 & 0.07 & 3.43 & 1.86 \\
\hline
\end{tabular}

a) obtained from bulk analyses; b) determined using cuprizone method (spectrophotometric method).

For $\mathrm{NaY}$ and the heterogeneous catalysts, the $\mathrm{Si} / \mathrm{Al}$ ratio was 2.80 as determined by $\mathrm{XRD}$ and 2.88 as measured by FTIR [21,22], which indicates the absence of dealumination during the encapsulation processes. The encapsulation methods employed lead to similar copper loading. The $\mathrm{C} / \mathrm{N}$ ratio for $\mathrm{CuL} @ \mathrm{NaY}_{\mathrm{A}}$ is triple for that obtained for the free complex. This suggests that some ligand destruction takes place during the complexation and that different complex species are formed. The elemental analysis results for $\mathrm{CuL}^{\prime} @ \mathrm{NaY}_{\mathrm{A}}$ suggest that $\mathrm{N}-\mathrm{N}$ bond cleavage of the ligand molecule occurs afford the corresponding bidentate Schiff base. Lterature data show that the hydrazone N-N bound can be cleaved in the presence of acetate anions [23]; it was suggested that the presence of the acetate ion plays an important role in this bound cleavage reaction. Furthermore, it was shown that the reaction is accelerated by the use of polar solvents such as DMF and THF. The literature data [23] support the proposed structure of the complex with bidentate Schiff base ligands. For the complex with a bidentate Schiff base present in a $\mathrm{M} / \mathrm{L}^{\prime}$ ratio, in which $\mathrm{L}^{\prime}$ is the ligand after cleavage, the calculated $\mathrm{Cu} / \mathrm{N}$ ratio is 2.25 and the $\mathrm{C} / \mathrm{N}$ ratio is 6.00. These values are different from those found for $\mathrm{CuL}^{\prime} @ \mathrm{NaY}_{\mathrm{A}}$ in which $\mathrm{C} / \mathrm{N}$ is 9.20 and $\mathrm{Cu} / \mathrm{N}$ is 1.80 . This suggests that all copper species are coordinated and the two THF molecules are present. However, the $\mathrm{C} / \mathrm{N}$ ratio of $\mathrm{CuL} @ \mathrm{NaY}_{\mathrm{B}}$ is close to that of the free complex and suggests that the ligand structure is not affected by diffusion/complexation. The amount of copper obtained by elemental analysis indicates the presence of different copper species. The highest $\mathrm{Cu} / \mathrm{N}$ (1.86) ratio observed suggests the presence of a fraction of copper non-coordinated to the imida-salen ligand $(0.06 \% \mathrm{wt})$. It was found that a part of this copper could be located in framework at sites that are inaccessible by the ligand [24]. The coordinated copper species present the same sphere of coordination as the free complex with 1:1 M:L stoichiometry. The presence of different copper species could have an effect on the catalytic behaviour of the catalysts.

The free complex, the heterogeneous catalysts and the NaY were characterized by FTIR spectroscopy. The FTIR spectrum of the free complex, $[\mathrm{Cu}($ imida-salenshows that the $v(\mathrm{C}=\mathrm{N})$ bands at 1618 is shifted to a lower frequencies by $12 \mathrm{~cm}^{-1}$ compared with the imida-Salen ligand $\left(1606 \mathrm{~cm}^{-1}\right)$. This indicates that the ligand is coordinated to the metal ion through the nitrogen donor atom of the azomethine group [25]. Also, the characteristic band at $2222 \mathrm{~cm}^{-1}$ associated with the $\mathrm{C} \equiv \mathrm{N}$ vibration $[26,27]$ is identified in the FTIR spectrum of the ligand. This band was 
found in the complex at the same frequency, which suggests no interaction between the $\mathrm{C} \equiv \mathrm{N}$ group and the coordinated metal. The shift of thev(C-O) band to higher energy by $25 \mathrm{~cm}^{-1}$ in the complex spectrum $\left(1386 \mathrm{~cm}^{-1}\right)$ suggests that copper(II) also is bound through the oxygen atoms from the phenol groups. Further conclusive evidence of the coordination of the ligand to copper(II) is shown by the appearance of the weak low-frequency band at $549 \mathrm{~cm}^{-1}$ assigned to copper-nitrogen stretching vibrations [28]. The band due to $\mathrm{Cu}-\mathrm{O}$ vibration usually appears at lower energies $\left(<400 \mathrm{~cm}^{-1}\right)$, outside the measured range.

The FTIR spectrum of NaY zeolite displays a very intense broad band at around $3450 \mathrm{~cm}^{-1}$ with a poorly resolved shoulder at around $3600 \mathrm{~cm}^{-1}$ which can be attributed to the hydroxy groups in supercages and in sodalite cages respectively [29, 30]. In mid-IR region the spectrum shows a band at $1640 \mathrm{~cm}^{-1}$ characteristic of the $\delta\left(\mathrm{H}_{2} \mathrm{O}\right)$ mode of absorbed water [31]. The band at around $1020 \mathrm{~cm}^{-1}$ is usually attributed to the asymmetric stretching of $\mathrm{Al}-\mathrm{O}-\mathrm{Si}$ chain of zeolite, and the symmetric stretching and bending bands of the Al-O-Si framework of zeolite appear at around 730 and $510 \mathrm{~cm}^{-1}$, respectively [32]. The FTIR spectra of the heterogeneous catalysts are dominated by the strong bands attributed to the zeolite structure. No shifts or broadening of the zeolite vibration bands are observed upon encapsulation of the complex. This provides further evidence for the zeolite structure remaing unchanged after encapsulation of the complex. The intensities of peaks due to encapsulated complexes are weak because of their low loading in the zeolite structure, in agreement with the XRD analysis.

Additional structural information can be obtained by EPR and Raman spectroscopy. Powder EPR spectra of NaY, the free complex and the heterogeneous catalysts are shown in Fig. 3 and the spin Hamiltonian parameters of the heterogeneous catalysts are presented in Table 2.

Table 2. EPR spectral data of free complex [Cu(imida-salen)], CuL'@ $\mathrm{NaY}_{\mathrm{A}}$ and $\mathrm{CuL} @ \mathrm{NaY}_{\mathrm{B}}$

\begin{tabular}{lcc}
\hline \multicolumn{1}{c}{ Sample } & $\mathrm{g}_{\perp}$ & $\mathrm{g}_{\|}$ \\
\hline$[\mathrm{Cu}($ imida-salen $)]$ & 2.077 & 2.103 \\
$\mathrm{CuL} @ \mathrm{NaY}_{\mathrm{A}}$ & 2.043 & 2.082 \\
$\mathrm{CuL} @ \mathrm{NaY}_{\mathrm{B}}$ & 2.087 & 2.108 \\
\hline
\end{tabular}

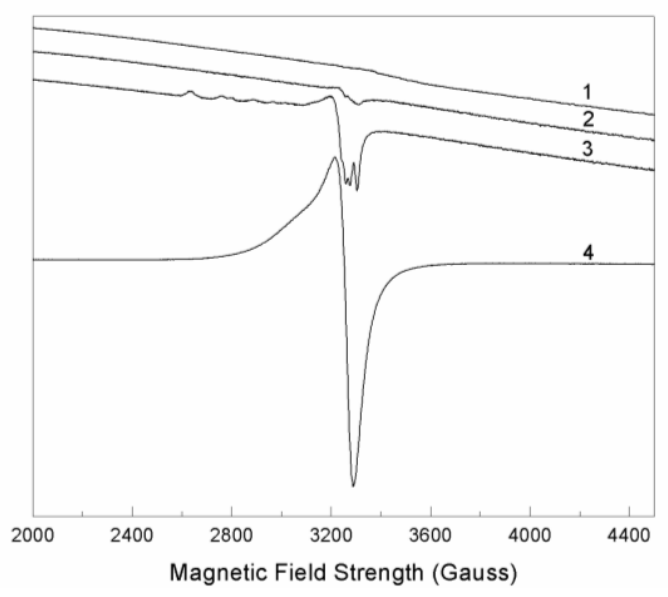

Figure 3. EPR spectra of (1) NaY, (2) CuL'@ $\mathrm{NaY}_{\mathrm{A}}$, (3) $\mathrm{CuL} @ \mathrm{NaY}_{\mathrm{B}}$ and (4) [Cu(imida-salen)].

All samples were cooled to $-196{ }^{\circ} \mathrm{C}$ prior to data acquisition to eliminate the effects of motional broadening that might appear at room temperature. It was shown that these spectra are typical of magnetically diluted samples dominated by high-spin copper(II) contributions [33], which implies that the $\mathrm{Cu}$ (II) complexes are dispersed within the zeolite supercages, acting as a diamagnetic matrix.

The spectra of the heterogeneous catalysts are different to those of $\mathrm{NaY}$ and the free complex. The spectral parameters of samples reveal that $\mathrm{g}_{\|}>\mathrm{g} \perp$, characteristic of an axially extended octahedral geometry. The EPR spectrum of the free complex is characterized by a signal at $\mathrm{g}=$ 2.077 and no hyperfine coupling due to copper was observed, probably due to nearest-neighbour molecular interactions [34]. In the EPR spectrum of $\mathrm{CuL} @ \mathrm{NaY}_{\mathrm{A}}$ the signal is lower and negligible hyperfine features was observed. These results suggest that all the copper species are 
coordinated and the resulting complex has a different coordination sphere to that of the free complex, in agreement with elemental analysis. However, the EPR spectrum of $\mathrm{CuL} @ \mathrm{NaY}_{\mathrm{B}}$ shows visible hyperfine features in the lower magnetic field region of the spectrum from the splitting of the $\mathrm{g}_{\|}$line, characteristic of ae copper nucleus with $\mathrm{I}=3 / 2[33,34]$. In our previous studies, we observed identical EPR results for copper(II)-methyladenine complex entrapped in NaBEA zeolite [35]. Likewise, for the CuL@NaY catalyst, the EPR results indicate the presence of different copper species dispersed in the diamagnetic host, which suggests the existence of a fraction of uncomplexed copper [34-36].

The Raman spectra of $\mathrm{NaY}$ and the heterogeneous catalysts are shown in Figure 4.

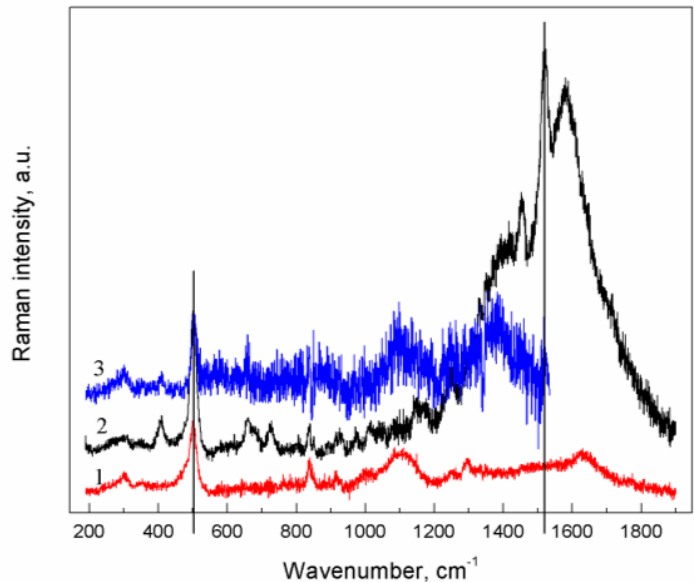

Figure 4. Raman spectra of $\mathrm{NaY}(1), \mathrm{CuL} @ \mathrm{NaY}_{\text {B }}$ (2) and CuL'@NaY $(3)$.

The spectra of the samples show intense fluorescence typically an order of magnitude more intense than the Raman signal. $\mathrm{NaY}$ and the heterogeneous catalysts exhibit a Raman band at $503 \mathrm{~cm}^{-1}$ attributed to the motion of the oxygen atom in a plane perpendicular to the T-O-T bonds in the zeolite structure [37]. The Raman spectrum of CuL'@ $\mathrm{NaY}_{\mathrm{A}}$ show higher fluorescence and the bands of this complex are rather faint being suffocated by this phenomenon. However, the spectrum of $\mathrm{CuL} @ \mathrm{NaY}_{\mathrm{B}}$ shows the bands at 1453, 1516 and 1586 $\mathrm{cm}^{-1}$. Similar bands were also observed in the FTIR spectrum of the free complex at 1452, 1515 and $1587 \mathrm{~cm}^{-1}$ which shows that the structure of the complex in $\mathrm{CuL} @ \mathrm{NaY} \mathrm{B}_{\mathrm{B}}$ is equivalent to that of the free complex.

Different forms of copper(II) complexes are considered in the DFT calculations. Figure 5 and Table 3 show the most relevant characteristics of their geometries (I-V), including the linear dimensions for each one, estimated from the electronic isodensity surface of 0.005 electronsBohr ${ }^{-3}$. The dimensions of these molecules are crucial for understanding the processes of encapsulation of the coordinated $\mathrm{Cu}$ (II) complexes. The NaY zeolite structure contains uniform-sized pores and cages [9], and therefore only active components with an appropriate size and shape can be incorporated. The diameter of the copper(II) complex with the imidasalen ligand is too large to effectively pass through the free aperture of the zeolite supercages (ca.7.4 A), but is small enough to be confined in the larger cavities (internal diameter ca.13 $\AA$ ) [38]. On the other hand, the tetradentate imida-salen ligand, due to its flexibility, can easily diffuse into the zeolite, and form complex, with previously exchanged metal atoms inside the supercages,in the case of $\mathrm{CuL} @ \mathrm{NaY}_{\mathrm{B}}$. 


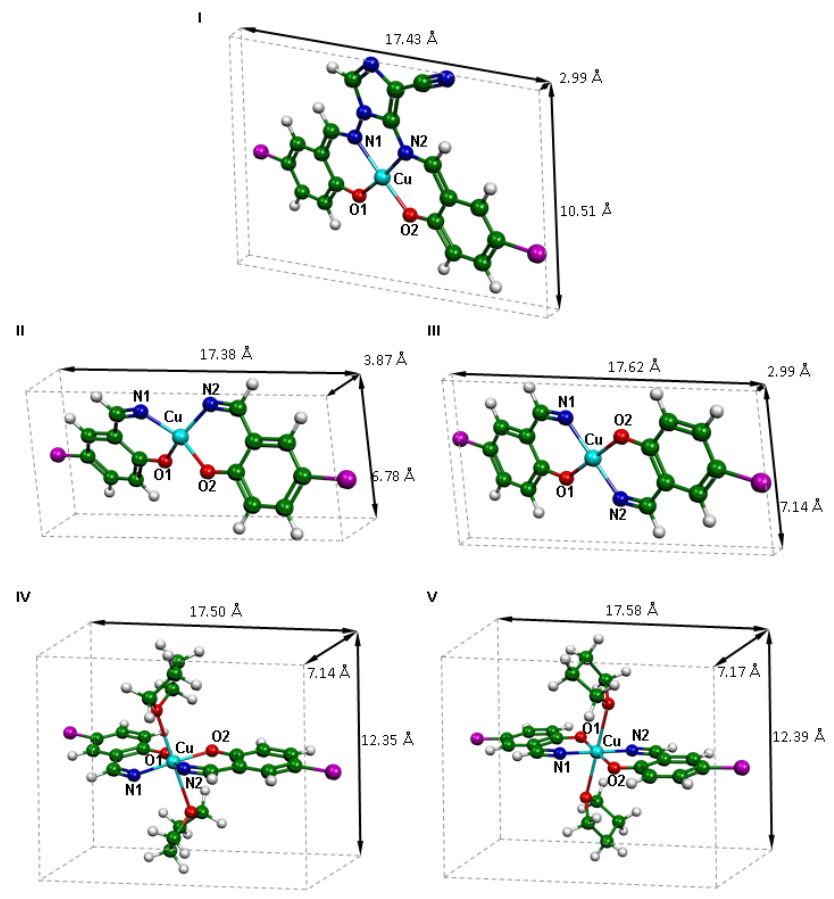

Figure 5. Optimized structures (I-V) for possible forms of the studied copper(II) complex determined by DFT calculations at the B3LYP/6-31G(d,p) level of theory. The boxes indicate the molecular dimensions size and volume, as estimated from the electronic isodensity surfaces of $0.005 e / a_{0}$.

Table 3. Optimized values of the most relevant geometrical parameters of the forms (I-V) $)^{\mathrm{a}}$ of the studied copper(II) complexes.

\begin{tabular}{cccccc} 
& \multicolumn{1}{c}{ I } & II & III & IV & V \\
\cline { 5 - 6 } $\begin{array}{c}\text { Distances/ } \\
\AA^{\mathrm{b}}\end{array}$ & & & & & \\
\cline { 1 - 1 } $\mathrm{Cu}-\mathrm{O} 1$ & 1.887 & 1.854 & 1.847 & 1.886 & 1.877 \\
$\mathrm{Cu}-\mathrm{O} 2$ & 1.875 & 1.854 & 1.848 & 1.886 & 1.877 \\
$\mathrm{Cu}-\mathrm{N} 1$ & 1.959 & 1.875 & 1.903 & 1.902 & 1.926 \\
$\mathrm{Cu}-\mathrm{N} 2$ & 1.958 & 1.875 & 1.903 & 1.903 & 1.927
\end{tabular}

$\underset{\mathrm{b}}{\text { Angles/ }^{\circ}}$

\begin{tabular}{cccccc}
\cline { 1 - 1 } $\begin{array}{c}\text { O1-Cu- } \\
\text { O2 }\end{array}$ & 91.76 & 93.56 & 179.97 & 87.93 & 179.99 \\
$\begin{array}{c}\text { N1-Cu- } \\
\text { N2 }\end{array}$ & 83.87 & 99.35 & 179.82 & 95.78 & 180.00 \\
$\begin{array}{c}\text { O1-Cu- } \\
\text { N1 }\end{array}$ & 91.04 & 90.37 & 88.88 & 88.31 & 88.54 \\
$\begin{array}{c}\text { O2-Cu- } \\
\text { N2 }\end{array}$ & 93.34 & 90.37 & 88.82 & 88.14 & 88.54
\end{tabular}




$\begin{array}{cccccc}\begin{array}{c}\text { O1-Cu- } \\ \text { N2 }\end{array} & 177.20 & 151.64 & 91.15 & 174.78 & 91.46 \\ \begin{array}{c}\text { O2-Cu- } \\ \text { N1 }\end{array} & 174.90 & 151.63 & 91.14 & 175.24 & 91.46\end{array}$

\begin{tabular}{|c|c|c|c|c|c|}
\hline Dihedral/ & & & & & \\
\hline $\begin{array}{l}\text { N1-O1- } \\
\text { O2-N2 }\end{array}$ & 0.00 & -39.17 & -0.13 & -4.59 & 0.01 \\
\hline
\end{tabular}

a) The numbering of the complex species is as indicated in Figure 5.b) Atom numbering as referred in Fig. 5.

The lengths of all forms of the copper(II) complexes are comparable, but there are noticeable differences in their widths and heights. These differences are the result of different geometries around the metal ion. All forms, except II, show planar geometry (omitting the solvent molecules).

The dimensions of the four-coordinated complexes with bidentate ligands (II and III) suggest an easier diffusion into and out of the zeolite. Among the four forms mentioned above, IV is slightly more distorted than others. The pseudo-octahedral geometries of structures IV and V (Fig. 5) are completed by two Schiff base molecules (bidentate) and two THF (monodentate) in axial coordination. These forms are in agreement with the results of the elemental analysis found for CuL'@NaY

The form II shows a distorted tetrahedral geometry around the metal ion. The most relevant geometrical parameters of the optimized structures are presented in Table 3 (the atom numbering is as shown in Figure 5).

Morokuma and co-workers [39-41] defined the stabilization energy as the difference between the energy of the global system and the total energy of separate components: $\Delta \mathrm{E}=\mathrm{E}_{\text {complex }}$ $\Sigma \mathrm{E}_{\text {component }}$ The different stabilities obtained for the complexes are presented in Table 4 . The most stable structure is that of the form (I) with a four-donor ligand. The stabilization energy is comparable for cis and trans isomers for both coordination environments (six-coordinate and four-coordinate forms). The results show that the cis isomers are more stable than the corresponding trans isomers and that the six-coordinate complexes are more stable than the four-coordinate complexes with two-donor ligands.

The stability of the optimized forms can be also be confirmed by the hardness parameter $(\eta)$. The hardness can be calculated by DFT, in general, by using simple orbital theory, which allows the hardness to be computed as the energy difference between the lowest-unoccupied molecular orbital (LUMO) and the highest-occupied orbital (HOMO), $\eta=($ ELUMO EHOMO)/2 [42]. Higher values of $\eta$ suggest lower molecular reactivity and hence higher stability. The values depicted in Table 4 confirm that the most stable and less reactive is the form (I) with a four-donor ligand.

Table 4. Energy stabilization $(\Delta \mathrm{E})$ and molecular hardness $(\eta)$ of the forms $(\mathrm{I}-\mathrm{V})$ a of the studied copper(II) complexes.

\begin{tabular}{cccccc}
\hline & I & II & III & IV & V \\
\hline $\begin{array}{c}\Delta \mathrm{E} \\
{[\mathrm{eV}]}\end{array}$ & -34.32 & -30.26 & -30.20 & -30.74 & -30.72 \\
$\eta[\mathrm{eV}]$ & 1.51 & 0.86 & 0.83 & 0.87 & 0.87 \\
\hline
\end{tabular}

a) The numbering of the complex species is as indicated in Figure 5.

The molecular hardness (Table 4), molecule dimensions and elemental analyses suggest that the structure of the complex encapsulated by method A, CuL'@ $\mathrm{NaY}_{\mathrm{A}}$ is six-coordinate with two THF coordinated in the axial positions, whereas in the case of $\mathrm{CuL} @ \mathrm{NaY}_{\mathrm{B}}$, the molecular structure of the free complex is retained in the zeolite matrix. 


\section{Catalytic behaviour of the catalysts}

\section{Oxidation of cyclohexanol}

The heterogeneous catalysts were evaluated for the oxidation of cyclohexanol (CyOL) to cyclohexanone (CyONE) in the presence of $\mathrm{tBuOOH}$ as the oxygen source. The extent of oxidation of cyclohexanol is negligible in the absence of the heterogeneous catalysts, which confirms that the is indeed catalytic in nature under experimental coditions. The zeolite $\mathrm{NaY}$ is also catalytically inactive and $\mathrm{Cu}-\mathrm{NaY}$ show a minor conversion (3.6\%). Thus, the copper complexes encapsulated into the zeolite play a decisive role. The catalysis results presented in Table 5 show that both heterogeneous catalysts as well as the free complex display comparable activities in cyclohexanol oxidation. Similar conversions of cyclohexanol with the homogeneous and $\mathrm{CuL} @ \mathrm{NaY}_{\mathrm{B}}$ was observed probably because the encapsulation method only slightly affects the accessibility of the active centre [43]. However, CuL'@ $\mathrm{NaY}_{\mathrm{A}}$ shows the same substrate conversion as the homogenous catalyst after $24 \mathrm{~h}$ of reaction. The ligand in the $\mathrm{CuL} @ \mathrm{NaY}_{\mathrm{A}}$ catalyst induces changes in the electron density of copper, which, in turn, probably modifies the catalytic properties of the metal centre. Consequently, the choice of the stable ligand is of crucial importance in the heterogenization of catalytic metal complexes.

Table 5. Selective oxidation of cyclohexanol to cyclohexanone in the presence of $\mathrm{tBuOOH}$ as oxygen source.

\begin{tabular}{|c|c|c|c|c|c|c|}
\hline Entry & catalyst & $\mathrm{T}^{\mathrm{a} / \mathrm{h}}$ & $\% \mathrm{C}^{\mathrm{b}, \mathrm{c}}$ & $\% \mathrm{~S}_{\mathrm{CyONE}}{ }^{b, \mathrm{~d}}$ & $\% \eta_{\mathrm{CyONE}}{ }^{\mathrm{b}, \mathrm{e}}$ & $\mathrm{TON}^{\mathrm{f}}$ \\
\hline 1 & {$[\mathrm{Cu}(\text { imida-salen })]^{\mathrm{g})}$} & 5 & 50 & 100 & 50 & 3085 \\
\hline 2 & $\mathrm{CuL} @ \mathrm{NaY}_{\mathrm{A}}$ & 24 & 51 & 100 & 51 & 2083 \\
\hline 3 & $\mathrm{CuL} @ \mathrm{NaY}_{\mathrm{B}}$ & 48 & 46 & 100 & 46 & 1301 \\
\hline
\end{tabular}

a) Reaction time at which the substrate conversion starts to become constant; b) Determined by GC against an internal standard; c) Cyclohexanol conversion $(\%$ C) calculated as: $\left.\left.\mathrm{C}=\left\{\left[\mathrm{A}_{(\mathrm{CyOL})} / \mathrm{A}_{(\mathrm{PhCl})}\right]_{\mathrm{t}=0 \mathrm{~h}} \times\left[\mathrm{A}_{(\mathrm{CyOL})} / \mathrm{A}_{(\mathrm{PhCl}}\right]_{\mathrm{t}=\mathrm{xh}}\right\} \times 100 /\left[\mathrm{A}_{(\mathrm{CyOL})}\right) / \mathrm{A}_{(\mathrm{PhCl})}\right]_{\mathrm{t}=0 \mathrm{~h}} ; \mathrm{d}\right)$ Product selectivity $(\%$

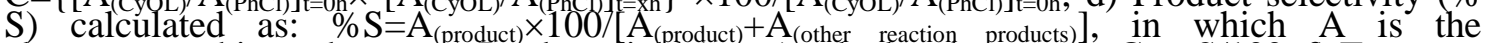
chromatographic peak area; $\mathrm{e}$ ) Product yield $(\% \eta)$ calculated as $\% \eta=\% \mathrm{C} \times \% \mathrm{~S} / 100 ; \mathrm{f})$ Turnover number (TON) calculated as: $\left.\mathrm{TON}=\% \mathrm{C} \times \mathrm{n}_{\mathrm{CyOL}} / \mathrm{n}_{\mathrm{Cu}} ; \mathrm{g}\right)\left(\mathrm{Cu}\right.$ loading $\left.=9.4 \times 10^{-4} \mathrm{mmol}\right)$

In our previous studies a series of transition metal complexes with 1-(2-pyridyazo)-2-naphtol (PAN) and a $\mathrm{Mn}(\mathrm{III})$ complex with 1,3-ditolyltriazene ligand were encapsulated into $\mathrm{NaY}$ by the flexible ligand method and tested as catalysts in the oxidation of cyclohexanol $[14,44]$ in the presence of tBuOOH. Cobalt(II) and nickel(II) complexes with PAN and a manganese(III) complex with triazenido ligands show lower substrate conversions than the catalysts studied in this work. CuL'@ $\mathrm{NaY}_{\mathrm{A}}$ as catalyst shows higher cyclohexanol conversion and $\mathrm{CuL} @ \mathrm{NaY}_{\mathrm{B}}$ and $\mathrm{Cu}(\mathrm{PAN}) @ Y$ lead to the same conversion. Most probably, the catalytically active species in $\mathrm{CuL} @ \mathrm{NaY}_{\mathrm{A}}$ are easily accessible by the substrate and oxidizing reagents due to the lability of THF.

Indirect comparison of the activities of previously reported solid catalysts with the catalysts presented here in the oxidation of cyclohexanol in the presence of $\mathrm{tBuOOH}$ shows that the copper-containing catalysts (this study) show lower activity than cobalt and copper nitrogendonor complexes (ethylenediamine or pyridine) immobilized on bentonite [43, 45]. On the other hand, the heterogeneous catalysts prepared show similar activity to supported cobalt oxide [43] and $[\mathrm{Cu}($ salen $)]$ and $[\mathrm{Cu}(\mathrm{acac})]$ complexes immobilized on bentonite [45] and higher activity than chromium silica-supported catalysts $(\% \mathrm{C}=40)$ [46], zirconium-doped manganese oxide materials (\%C $=13-18)$ [47] and cobalt Salen type complexes immobilized on bentonite [43].

The recyclability of the heterogeneous catalysts was also evaluated. After the catalyst had been used, it was recovered by filtration, washed several times with EtOH and ACN, subsequently dried at $100{ }^{\circ} \mathrm{C}$ and then reused. The catalysts could be used twice without significant change in their catalytic activity.

\section{Oxidation of phenol}

In contrast to the oxidation of cyclohexanol, in which the predominant product is cyclohexanone with only a trace amount of 2-cyclohexen-1-one detected, under specific conditions [48], the oxidation of phenol can lead to a variety of products [49, 50]. It was shown that solvent properties (polarity, hydrophobicity and size) affect the reaction rate [51] and that 
acetonitrile medium leads to the best results (maximum phenol conversion). Under the experimental conditions employed in this study (solvent: ACN, oxygen source: $\mathrm{tBuOOH}$ ) the main phenol oxidation product was catechol (CAT). A trace amount of hydroquinone (HQ) was detected when the reaction was performed in the heterogeneous phase after $24 \mathrm{~h}$ (Table 6). The $\mathrm{NaY}$ zeolite did not exhibit catalytic activity in the oxidation of phenol under the applied experimental conditions. The oxidation reaction leads to higher substrate conversion in the heterogeneous phase. This result confirms the above-mentioned hypothesis that the preparation by the flexible ligand method allows access to the active sites. Similarly to the oxidation of cyclohexanol the CuL@ $@ \mathrm{NaY}_{\mathrm{A}}$ catalyst shows higher substrate conversion than under homogeneous conditions. However, those results cannot be directly compared. There are many examples in the literature [52-55] confirming the trend observed in our study; that phenol conversion is higher under heterogeneous conditions. This may be due to active-site separation in heterogeneous catalysts, whereas the free $\mathrm{Cu}$ (II) complexes have tendencies to form dimers [56].

Table 6. Results for the oxidation of phenol catalysed by the encapsulated and free copper(II) complexes.

\begin{tabular}{|c|c|c|c|c|c|c|c|c|}
\hline \multirow{3}{*}{ Entry } & \multirow{3}{*}{ Catalysts } & \multirow{3}{*}{$\mathrm{T}^{\mathrm{a})} / \mathrm{h}$} & \multirow{3}{*}{$\% \mathrm{C}^{\mathrm{b}, \mathrm{c}}$} & \multicolumn{4}{|c|}{ Products } & \multirow{3}{*}{$\mathrm{TON}^{\mathrm{f}}$} \\
\hline & & & & \multicolumn{2}{|c|}{ CAT } & \multicolumn{2}{|c|}{ HQ } & \\
\hline & & & & $\% \mathrm{~S}^{\mathrm{b}, \mathrm{d}}$ & $\% \eta^{\mathrm{b}, \mathrm{e}}$ & $\% \mathrm{~S}^{\mathrm{b}, \mathrm{d}}$ & $\% \eta^{\mathrm{b}, \mathrm{e}}$ & \\
\hline 4 & {$[\mathrm{Cu}(\text { imida-salen })]^{\mathrm{g}}$} & 4 & 27 & 100 & 27 & ND & ND & 287 \\
\hline 5 & $\mathrm{CuL} @ \mathrm{NaY}_{\mathrm{A}}$ & 48 & 46 & 99 & 45 & 1 & $>1$ & 324 \\
\hline 6 & $\mathrm{CuL} @ \mathrm{NaY}_{\mathrm{B}}$ & 48 & 34 & 98 & 33 & 2 & $>1$ & 166 \\
\hline
\end{tabular}

a) Reaction time at which the substrate conversion starts to become constant; b) Determined by GC against internal standard; c) Phenol conversion (\% C) calculated as: \% $\mathrm{C}=$ $\left.\left\{\left[\mathrm{A}_{(\mathrm{PhOH})} / \mathrm{A}_{(\mathrm{PhCl})}\right]_{t=0 h} \times\left[\mathrm{A}_{(\mathrm{PhOH})} / \mathrm{A}_{(\mathrm{PhCl})}\right]_{\mathrm{t}=\mathrm{xh}}\right\} \times 100 /\left[\mathrm{A}_{(\mathrm{PhOH})} / \mathrm{A}_{(\mathrm{PhCl})}\right]_{\mathrm{t}=0 \mathrm{~h}} ; \mathrm{d}\right)$ Product selectivity (\% $\left.\mathrm{S}\right)$ calculated as: $\% \mathrm{~S}=\mathrm{A}_{\text {(product) }} \times 100 \%\left[\mathrm{~A}_{\text {(product) }}+\mathrm{A}_{\text {(other reaction products })}\right]$, where $\mathrm{A}$ stands for chromatographic peak area; e) Product yield $(\% \eta \eta)$ calculated as $\% \eta=\% \mathrm{C} \times \% \mathrm{~S} / 100$; Turnover number (TON) calculated as: $\mathrm{TON}=\% \mathrm{C} \times \mathrm{n}_{\mathrm{PhOH}} / \mathrm{n}_{\mathrm{Cu}} \mathrm{g}$ ) $\mathrm{Cu}$ loading $=9.4 \times 10^{-4} \mathrm{mmol}$

The catalytic properties of the copper(II) Schiff base complexes encapsulated into zeolites in the oxidation of phenol have been studied previously by others $[32,51,52,54,57,58]$. All the heterogeneous catalysts studied are active towards phenol oxidation and lead to catechol formation as the main product. A comparison of these catalysts with those presented in this study shows that $\mathrm{CuL} @ \mathrm{NaY}_{\mathrm{B}}$ exhibit slightly higher phenol conversion than copper(II) complexes with substituted Salen ligands [51,59] when ACN was used as solvent., whereas the $\mathrm{CuL} @ \mathrm{NaY}_{\mathrm{A}}$ catalyst shows activity close to copper(II) complexes with tridentate Schiff bases $[52,58]$.

The recyclability of the heterogeneous catalysts ws also evaluated. After the catalyst had been used it was recovered by filtration, washed several times with EtOH and ACN, and subsequently dried at $100{ }^{\circ} \mathrm{C}$ then reused. The catalysts were could be used twicewithout significant change in their catalytic activity.

\section{Oxidation of hydroquinone}

The oxidation of hydroquinone to benzoquinone (BzQ) is being extensively investigated with the dual objectives of removing phenolic waste from industrial effluents and achieving useful products. Metal complexes have been found to efficiently catalyse this reaction [1, 60-63]. The catalysts evaluated in this study also show high catalytic activity in this reaction (Table 7). Both heterogeneous catalysts show similar substrate conversion and this is in accordwith literature data [62] which suggest that four coordinate $\mathrm{Cu}$ (II) complexes of the $\mathrm{N}_{2} \mathrm{O}_{2}$ type show the highest catalytic activity in the oxidation of hydroquinone.

Benzoquinone is the main oxidation product with selectivity always higher than $80 \%$. The lack of literature data of the hydroquinone conversion may be due to that this strongly depends on metal loading [63]. 
Table 7. Hydroquinone decomposition

\begin{tabular}{ccccc}
\hline Entry & Catalyst & Time $^{\mathrm{a}}$ & \%C $^{\mathrm{b}, \mathrm{c}}$ & TON $^{\mathrm{d}}$ \\
\hline 7 & {$[\mathrm{Cu}(\text { imida-salen })]^{\mathrm{e}}$} & 5 & 80 & 5.74 \\
8 & $\mathrm{CuL} @ \mathrm{NaY}_{\mathrm{A}}$ & 48 & 84 & 3.99 \\
9 & $\mathrm{CuL} @ \mathrm{NaY}_{\mathrm{B}}$ & 48 & 86 & 2.83
\end{tabular}

a) Reaction time at which the substrate conversion starts to become constant; $b$ ) Determined by UV-VIS $\lambda=288 \mathrm{~nm} ;$ c) HQ conversion $\left(\%\right.$ C) calculated as: $\% \quad \mathrm{C}=\left\{\left[\mathrm{A}_{(\mathrm{HO})}\right]_{\mathrm{t}=0 \mathrm{~h}^{-}}\right.$ $\left.\left[\mathrm{A}_{(\mathrm{HO})}\right]_{t=x h}\right] \times 100 /\left[\mathrm{A}_{(\mathrm{HQ})}\right]_{\mathrm{t}=0 \mathrm{~h}}$ in which $\mathrm{A}$ is the absorbance.; $\left.\mathrm{d}\right)$ Turnover number $(\mathrm{TON})$ calculated as: $\left.\mathrm{TON}=\% \mathrm{C} \times \mathrm{n}_{\mathrm{HQ}} / \mathrm{n}_{\mathrm{Cu}} ; \mathrm{e}\right) \mathrm{Cu}$ loading $=9.4 \times 10^{-4} \mathrm{mmol}$

For all heterogeneous catalysts studied, after the last catalytic cycle, the IR spectra of the zeolite host showed no significant changes, which suggests that no structural changes took place on the zeolite host during the catalytic reaction. The leaching test was carried out according to the recommendation of Arends and Sheldon [64] and no reaction progress was observed after catalysts isolation. This confirms the high activity of the catalysts in the second reactions cycle.

\section{Conclusions}

Heterogeneous catalysts based on copper(II) complexes with the 1,5-bis((E)-5-chloro-2hydroxybenzylideneamino)-1H-imidazole-4-carbonitrile ( $\mathrm{H}_{2}$ imida-salen $)$ ligand have been synthesised and encapsulated into $\mathrm{NaY}$ zeolite by two different methods (A and $\mathrm{B}$ ). The catalysts obtained by these methods are different. In CuL@ $\mathrm{NaY}_{\mathrm{B}}$ the imida-salen ligand retains its integrity and the complex has the same coordination sphere as the free complex. In $\mathrm{CuL}^{\prime} @ \mathrm{NaY}_{\mathrm{A}}$, the ligand is cleaved and the copper(II) complex encapsulated into the zeolite is different to the free complex. These catalysts are environmentally benign in the liquid phase oxidation of cyclohexanol, phenol and hydroquinone in the presence of different oxygen sources. Both heterogeneous catalysts show high conversion in the oxidation of hydroquinone, and moderate conversion in the oxidation of phenol and cyclohexanol under optimized reaction conditions. The high selectivity towards catechol formation (ca.98\%) in the hydroxylation of phenol was observed for all catalysts.

\section{Experimental Section}

\section{Materials and reagents}

$\mathrm{NaY}$ zeolite $(\mathrm{CBV} 100, \mathrm{Si} / \mathrm{Al}$ ratio $=2.83)$ in powder form was obtained from Zeolyst International. The powder was calcined at $500{ }^{\circ} \mathrm{C}$ during $8 \mathrm{~h}$ under a stream of dry air prior to use. All chemicals and solvents were reagent grade and purchased from Aldrich: cuprizone, 2hydroxyphenylaldehyde, copper(II) acetate monohydrate $\left(\mathrm{Cu}\left(\mathrm{CH}_{3} \mathrm{COO}\right)_{2} \cdot \mathrm{H}_{2} \mathrm{O}\right)$, tetrahydrofurane (THF), acetonitrile (ACN), dimethylformamide (DMF), dichloromethane $(\mathrm{DCM})$, ethanol (EtOH), diethyl ether (DE), tert-butyl hydroperoxide solution - 5.0-6.0 $\mathrm{M}$ in decane $(\mathrm{tBuOOH})$, hydrogen peroxide solution $-30 \mathrm{wt}$. \% in water, chlorobenzene $(\mathrm{PhCl})$, styrene, phenol (PhOH), catechol (CAT), cyclohexanol (CyOL) and hydroquinone (HQ). Trifluoroacetic (TFA) acid was purchased from ACROS. The potassium bromide used for the FTIR pellets preparation was from Merck, spectroscopic grade.

\section{1,5-Bis((E)-5-chloro-2-hydroxybenzylideneamino)-1H-imidazole-4-carbonitrile ligand and free complex}

5-chloro-2-hydroxy-benzaldehyde $(0.85 \mathrm{~g}, 5.32 \mathrm{mmol})$ and trifluoroacetic acid $(0.40 \mathrm{~mL}, 5.32$ $\mathrm{mmol})$ were added to a suspension of 1,5-diamino-4-cyanoimidazole [65] $(0.33 \mathrm{~g}, 2.66 \mathrm{mmol})$ in ethanol, whilst stirring, at room temperature. When TLC indicated the absence of the starting material, the reaction mixture was cooled to $0{ }^{\circ} \mathrm{C}$ for $10 \mathrm{~min}$. The yellow solid was filtered under vacuum and washed with cold EtOH and DE. The product was identified as 1,5-bis $((E)-5-$ chloro-2-hydroxybenzylideneamino)- $1 \mathrm{H}$-imidazole-4-carbonitrile $\left(\mathrm{H}_{2}\right.$ imida-salen, $0.8 \mathrm{~g}, 2.19$ mmol, 82\%; Scheme 1) m.p. $=295-296{ }^{\circ} \mathrm{C} ;{ }^{1} \mathrm{H}$ NMR (400 MHz, DMSO-d6) $\delta_{\mathrm{H}} 11.34(\mathrm{~s}, 1 \mathrm{H}$, $\left.\mathrm{HO}_{\mathrm{A}}\right), 10.84\left(\mathrm{~s}, 1 \mathrm{H}, \mathrm{HO}_{\mathrm{B}}\right), 9,31\left(\mathrm{~s}, 1 \mathrm{H}, \mathrm{C}=\mathrm{H}_{\mathrm{A}}\right), 9.19\left(\mathrm{~s}, 1 \mathrm{H}, \mathrm{C}=\mathrm{H}_{\mathrm{B}}\right), 8.49(\mathrm{~s}, 1 \mathrm{H}, \mathrm{H}-2), 7.86(\mathrm{~d}, \mathrm{~J}$ $\left.=2.8 \mathrm{~Hz}, 1 \mathrm{H}, \mathrm{Ho}^{\prime \prime}\right), 7.79$ (d, J = 2.8 Hz, 1H, Ho), 7.47 (dd, J = 2.8; $8.8 \mathrm{~Hz}, 1 \mathrm{H}, \mathrm{Hp}$ ), 7.47 (dd, 
$\mathrm{J}=2.8 ; 8.8 \mathrm{~Hz}, 1 \mathrm{H}, \mathrm{Hp}), 7.02\left(\mathrm{~d}, \mathrm{~J}=8.8 \mathrm{~Hz}, 1 \mathrm{H}, \mathrm{Hm}^{\prime}\right), 7.01\left(\mathrm{~d}, \mathrm{~J}=8.8 \mathrm{~Hz}, 1 \mathrm{H}, \mathrm{Hm}^{\prime \prime \prime}\right) . \delta_{\mathrm{C}}(100$ MHz, DMSO-d6) 161.08 $\left(\mathrm{C}_{\mathrm{a}}\right), 158.57\left(\mathrm{C}_{\mathrm{o}^{\prime \prime \prime}}\right), 157.25\left(\mathrm{C}_{\mathrm{o}}{ }^{\prime}\right), 155.34\left(\mathrm{C}_{\mathrm{b}}\right), 143.56(\mathrm{C} 5), 134.31$ $\left(\mathrm{C}_{\mathrm{p}^{\prime} \mathrm{A}}\right), 133.58\left(\mathrm{C}_{\mathrm{pB}}\right), 133.03(\mathrm{C} 2), 127.48\left(\mathrm{C}_{\mathrm{o}^{\prime \prime} \mathrm{A}}\right), 126.05\left(\mathrm{C}_{\mathrm{oB}}\right), 123.49,123.39\left(\mathrm{C}_{\mathrm{m}^{\prime \prime} \mathrm{A}}\right.$ and $\left.\mathrm{C}_{\mathrm{mB}}\right)$, $122.00\left(\mathrm{C}_{\mathrm{i}^{\prime} \mathrm{A}}\right), 119.88\left(\mathrm{C}_{\mathrm{BB}}\right), 118.89,118.66\left(\mathrm{C}_{\mathrm{m}^{\prime} \mathrm{A}}\right.$ and $\left.\mathrm{C}_{\mathrm{m}^{\prime \prime \prime} \mathrm{A}}\right), 115.45(\mathrm{CN}), 101.11(\mathrm{C} 4) \mathrm{ppm}$. $\mathrm{C}_{18} \mathrm{H}_{11} \mathrm{Cl}_{2} \mathrm{~N}_{5} \mathrm{O}_{2}(400.22)$ Calcd. C, 54.02; H, 2.77; Cl, 17.72; N, 17.50; found C, 54.10; H, 2.81; N, 17.76 .

The free complex, [Cu(imida-salen)] was synthesized in THF. $\mathrm{Cu}(\mathrm{II})$ acetate monohydrate (97.6 $\mathrm{mg}, 0.49 \mathrm{mmol})$ and the Schiff base ligand $(198.6 \mathrm{mg}, 0.50 \mathrm{mmol})$ were dissolved in thf $(190$ $\mathrm{mL}$ ), the solution was heated at reflux for $2 \mathrm{~h}$ and a brown solid was separated by filtration. Elemental analysis of the $[\mathrm{Cu}($ imida-salen $)]$ complex confirmed the purity of the compound obtained and proved that the Schiff base complex was formed with a metal: ligand 1:1 molar ratio. $[\mathrm{Cu}$ (imida-salen) $] \times \mathrm{THF}$ was formed as a brown solid in a yield of $85 \% . \mathrm{C}_{22} \mathrm{H}_{17} \mathrm{CuN}_{5} \mathrm{O}_{3} \mathrm{Cl}_{2}$ (533.86): C, 49.50; H, 3.21; N, 13.12; Cu, 11.90; found: C, 48.99; H, 2.88; N, 13.55; Cu, 11.43.

\section{Encapsulation of $\mathrm{Cu}(\mathrm{II})$ imida-salen complex in $\mathrm{NaY}$}

The procedure for the preparation of the zeolite-based catalysts has been described elsewhere [44]. Method A: In this method only one step is involved. A solution of the imida-salen ligand (136.0 $\mathrm{mg}, 0.34 \mathrm{mmol}$ ) and copper(II) acetate monohydrate $(62.0 \mathrm{mg}, 0.31 \mathrm{mmol})$ in THF (100 $\mathrm{mL}$ ) was added to a suspension of NaY zeolite $(2.0 \mathrm{~g}$ in $100 \mathrm{~mL}$ of THF) under constant stirring for $48 \mathrm{~h}$. The solid was filtered and Soxhlet extracted with THF, EtOH and DCM until the elut became colourless. The new catalyst, $\mathrm{CuL}$ '@ $\mathrm{NaY}_{\mathrm{A}}$, in which L' is a derivate of the imida-salen ligand, was dried in an oven at $60^{\circ} \mathrm{C}$ overnight under reduced pressure.

Method B: In this method, the in situ synthesis involves two steps. In the first step, cation exchange in $\mathrm{NaY}$ zeolite was performed with an aqueous solution of copper(II) acetate monohydrate $(0.0640 \mathrm{~g}, 0.32 \mathrm{mmol})$ per $2.0 \mathrm{~g}$ of NaY previously dried at $150^{\circ} \mathrm{C}$ for $12 \mathrm{~h}$. The resulting mixture was stirred for $24 \mathrm{~h}$ at room temperature and a pale blue suspension was obtained. The solid was filtered and dried in an oven at $60{ }^{\circ} \mathrm{C}$ for $12 \mathrm{~h}$ and finally dried in vacuo for $2 \mathrm{~h}$. The copper-exchanged $(\mathrm{Cu}-\mathrm{NaY})$ zeolite $(1.80 \mathrm{~g})$ was suspended in a solution of imidasalen $(103 \mathrm{mg}, 0.27 \mathrm{mmol})$ in THF $(65 \mathrm{~mL})$. The resulting solid was filtered and washed with deionised water and $\mathrm{EtOH}$, and then dried at $60^{\circ} \mathrm{C}$ under reduced pressure overnight. The solid was then Soxhlet extracted subsequently with THF, EtOH and DCM until the eluent became colourless. The new catalyst $\mathrm{CuL} @ \mathrm{NaY}_{\mathrm{B}}$, in which $\mathrm{L}$ is the imida-salen ligand, was dried in the oven at $60^{\circ} \mathrm{C}$ overnight under reduced pressure.

\section{Characterisation methods}

NMR spectra were obtained with a Varian Unity Plus Spectrometer at an operating frequency of $300 \mathrm{MHz}$ for ${ }^{1} \mathrm{H}$ NMR and $75.4 \mathrm{MHz}$ for ${ }^{13} \mathrm{C}$ NMR or with a Bruker Avance III 400 at an operating frequency of $400 \mathrm{MHz}$ for ${ }^{1} \mathrm{H}$ NMR and $100.6 \mathrm{MHz}$ for ${ }^{13} \mathrm{C}$ NMR using the solvent peak as an internal reference at $25^{\circ} \mathrm{C}$. Powder EPR spectra of free and heterogeneous catalysts were collected with a Bruker EMX EPR spectrometer at $-196^{\circ} \mathrm{C}$ using a finger Dewar inserted into a Bruker standard ER4102ST cavity. The microwave frequency was around $9.42 \mathrm{GHz}$. Before acquisition of the EPR spectra, the samples were dried overnight at $120^{\circ} \mathrm{C}$. Unpolarized Raman spectra were collected at room temperature with excitation radiation in the visible range. Emission lines of $488 \mathrm{~nm}$ and $514.5 \mathrm{~nm}$ from Argon laser were used. The silicon transverse optical (TO) mode at $521 \mathrm{~cm}^{-1}$ was used as calibration frequency reference. A prism monochromator was used to avoid the incidence of Argon laser plasma lines on the sample. The experiments were performed by using a Jobin Yvon T64000 spectrometer with an optical microanalysis system and a CCD detector. The spectral resolution was approximately $1 \mathrm{~cm}^{-1}$ within a backscattering geometry scattering configuration. A $100 \times$ objective was employed to focus the laser light. To avoid sample damage the incident power was kept under $4 \mathrm{~mW}$ with a spot diameter of approximately $1 \mu \mathrm{m}$. To verify the reproducibility of the experiments several measurements were carried out in the same point with different time exposure to certify that the experimental conditions did not alter the physical properties of the samples. In addition, $n$ Raman spectra were collected from different regions of each sample to verify their homogenity. Elemental analysis $(\mathrm{C}, \mathrm{H}, \mathrm{N})$ were carried out with a Leco CHNS-932 analyser. HRMS were obtained with a GV AutoSpec spectrometer using m-nitrobenzyl alcohol (NBA) as matrix. The copper in the free complex was analysed by aspectrophotometric method. The copper loading in the zeolitic samples was evaluated according to the SMEWW 3120 method, using Inductively 
Coupled Plasma (ICP) with an ICP-AES Horiba Jobin-Yvon Ultima instrument at the Laboratório de Análises of the Instituto Superior Técnico, Portugal. Powder X-ray diffraction patterns (PXRD) were recorded with a Philips Analytical X-ray PW1710 BASED diffractometer system. The solids samples were exposed to $\mathrm{Cu} \mathrm{K \alpha}$ radiation at room temperature in the $2 \Theta$ range of $5-65^{\circ}$. The relative crystallinity of the heterogeneous catalysts was estimated by comparing the intensities of the peaks with those of $\mathrm{NaY}$ used as a standard sample (100\% crystalline). The total intensities of the six peaks assigned to [3 3 1], [ [ 511 1], [4 4 0], [ [ $\left.\begin{array}{lll}5 & 3 & 3\end{array}\right],\left[\begin{array}{lll}6 & 4 & 2\end{array}\right]$ and [ $\left[\begin{array}{lll}5 & 5 & 5\end{array}\right]$ reflections were used for the comparison according by the ASTM D-3906-80 method. The unit cell parameters $\left(a_{0}\right)$ were calculated from the [ [ 53 3], [ [ 64 4 2] and [5 5 5] reflection peak positions using quartz as an internal standard by the ASTM D-3942-80 method. FTIR spectra were obtained, in the range of $500-4000 \mathrm{~cm}^{-1}$ with a BOMEM MB10 spectrophotometer by using $\mathrm{KBr}$ pellets, the materials were mixed in 1:150 ratio with $\mathrm{KBr}$,. All spectra were collected at room temperature, with a resolution of $4 \mathrm{~cm}^{-1}$ and 32 scans. The electronic UV/vis absorption spectra of the free compounds were collected in the range 600-200 $\mathrm{nm}$ in DMF, DCM and EtOH with a Shimadzu UV/2501PC spectrophotometer using quartz cells at room temperature. The GC-FID chromatograms were obtained with a SRI 8610C chromatograph equipped with a CP-Sil 8C capillary column. Nitrogen was used as the carrier gas. The reaction products were identified by GC-MS using a Varian 4000 Performance chromatograph.

\section{Computational details}

The geometries of all the possible species assumed by the copper(II) complexes were characterized by a quantum mechanical method based on DFT. The Becke's B3LYP threeparameter exchange-correlation hybrid functional with nonlocal correlation, provided by Lee, Yang, and Parr, was used [66-69]. The double-zeta Pople basis set 6-31G(d,p) was employed, which ensures a superior electronic description by adding polarization functions of the p- d-, and especially f-type for all hydrogen, non-hydrogen, and metal atoms, respectively. Full geometry optimization of the molecular systems was performed in the gas phase without any symmetry restriction. The geometry optimizations were always started with the metal ion out of the plane defined by the two oxygen and two nitrogen donor atoms, to avoid metastable structures. The vibration frequencies of all studied complexes were calculated at the same DFT level by employing a harmonic model, and considering the molecules as being isolated in the gas phase. No imaginary frequencies were obtained, which confirms that the molecular structures were optimized to local minima on the potential energy surface.

All geometry optimizations, as well as energy and frequency calculations were performed using the Gaussian-09 package of programs [70]. Graphical representations of the optimized structures and molecular orbitals were produced with the MOLEKEL 4.3 [71] and Gauss-View 5.0 molecular visualization programs [72].

\section{Catalytic oxidations}

All catalysts were dehydrated, in vacuo for $2 \mathrm{~h}$ at $120{ }^{\circ} \mathrm{C}$, prior to their use in the catalytic reactions. All blank experiments were performed under the same conditions as the catalysed reactions.

\section{Oxidation of cyclohexanol}

The reaction was carried out in acetonitrile $(4.0 \mathrm{~mL})$ at $40{ }^{\circ} \mathrm{C}\left( \pm 5^{\circ} \mathrm{C}\right)$ under constant stirring, with cyclohexanol $(0.6 \mathrm{~mL}, 5.8 \mathrm{mmol}$, substrate), chlorobenzene $(0.6 \mathrm{~mL}, 5.9 \mathrm{mmol}$, internal standard $)$ and the heterogeneous catalyst $(0.10 \mathrm{~g})$. The oxygen source, $\mathrm{tBuOOH}(2.0 \mathrm{~mL}$ of 5.5 $\mathrm{M}$ in decane solution), was progressively added to the reaction medium at a rate of $0.1 \mathrm{~mL} \times \mathrm{min}^{-}$ ${ }^{1}$. The progress of the reaction was monitored as a function of time by withdrawing portions of the sample at fixed time intervals and analysing by gas chromatography. The identities of the products were confirmed by comparison with authentic samples or by GC-MS. The products were quantitatively determined by an internal standard. At the end of each run, the heterogeneous catalysts were sequentially extracted/centrifuged with ethanol $(3 \times 10 \mathrm{~mL})$ and acn $(2 \times 10 \mathrm{~mL})$, and then dried in an oven at $100{ }^{\circ} \mathrm{C}$ overnight before the new catalytic cycle or characterization. The catalytic activity of the homogeneous counterpart, the [Cu(imida-salen)] complex, was also tested.

\section{Oxidation of phenol}

The reaction was carried out in acetonitrile $(6.0 \mathrm{~mL})$ at $70{ }^{\circ} \mathrm{C}\left( \pm 5^{\circ} \mathrm{C}\right)$ under constant stirring with phenol $(0.09 \mathrm{~g}, 1.0 \mathrm{mmol}$, substrate $)$, chlorobenzene $(0.11 \mathrm{~g}, 1.0 \mathrm{mmol}$, internal standard $)$ 
and heterogeneous catalyst $(0.10 \mathrm{~g})$. The oxygen source, tBuOOH $(0.2 \mathrm{~mL}$ of $5.5 \mathrm{M}$ in decane solution), was progressively added to the reaction medium at a rate of $0.02 \mathrm{~mL} \times \mathrm{min}^{-1}$. The reaction products were analysed and identified as mentioned above. Catalytic activity of the free complex under homogeneous conditions was tested. At the end of each run, the heterogeneous catalysts were sequentially extracted/centrifuged with ethanol $(3 \times 10 \mathrm{~mL})$ and acetonitrile $(2 \times 10$ $\mathrm{mL}$ ), and then dried in an oven at $100{ }^{\circ} \mathrm{C}$ overnight before the new catalytic cycle or characterization.

\section{Oxidation of hydroquinone}

The reaction was carried out in distilled water $(8.5 \mathrm{~mL})$ under constant stirringwith hydroquinone $\left[1.5 \mathrm{~mL}\right.$ of aqueous solution of hydroquinone $\mathrm{c}=3.0 \times 10^{-2} \mathrm{~mol} \times \mathrm{dm}^{-3}\left(6.75 \times 10^{-3}\right.$ $\mathrm{mmol})]$, the heterogeneous catalyst $(0.10 \mathrm{~g})$ and $30 \% \mathrm{H}_{2} \mathrm{O}_{2}$ as an oxygen source. During the experiments, aliquots $(0.3 \mathrm{~mL})$ were removed from solution with a hypodermic syringe, filtered through $0.2 \mu \mathrm{m}$ syringe filters and the absorbance was measured at $\lambda=288 \mathrm{~nm}$ using quartz cuvette $1=0.1 \mathrm{~cm}$. At the end of each run, the heterogeneous catalysts were sequentially extracted/centrifuged with $\mathrm{EOH}(3 \times 10 \mathrm{~mL})$ and two can $(2 \times 10 \mathrm{~mL})$, and then dried in an oven at $100{ }^{\circ} \mathrm{C}$ overnight and characterized.

Acknowledgments

IKB thanks the Fundação para Ciência e Tecnologia (FCT) for acontract under the program Ciência 2007. The authors are grateful to Dr A. S. Azevedo for collecting the powder diffraction data. The authors thank the FCT and the European Fund for Regional Development-(FEDER COMPETE-QREN-EU) for financial support to the Research Centre, (CQ/UM; PEstC/QUI/UI0686/2011,FCOMP-01-0124-FEDER-022716) and to the financial support to the NMR Portuguese Network (PTNMR, Bruker Avance III 400-Univ. Minho).

[1] X.-G. Meng, J. Zhu, J.Yan, J.-Q. Xie, X.-M. Kou, X.-F. Kuang, L.-F. Yu, X.-C. Zeng, J. Chem. Technol. Biotechnol. 2006, 81,2-7.

[2] O. P. Pestunova, O. L. Ogorodnikova, V. N. Parmon, Chem. Sustain Dev. 2003, 11, $227-$

[3] S. Caudo, G. Centi, Ch. Genovese, S. Perathoner, Appl. Catal. B: Environ. 2007, 70, 437446.

[4] S. Martínez-Méndez, Y. Henríquez, O. Domínguez, L. D’Ornelas, H. Krentzien, J. Mol. Catal. A: Chem. 2006, 252, 226-234.

[5] A. Castellan, J.C.J. Bart, S. Cavallaro, Catal. Today 1991, 9, 285-299.

[6] (a) G. B. Shulpin, M. G. Matthes, V. B. Romakh, M. I. F. Barbosa, J. L. T. Aoyagi, D. Mandelli, Tetrahedron 2008, 64, 2143-2152. (b) M. Jhansi, L. Kishore, K. A. Anand, A. Kumar, Catal. Commun. 2008, 10, 285-290. (c) S. K. Jana, Y. Kubota, T. Tatsumi, J. Catal. 2008, 255, 40-47.

[7] (a) I. Manninger, Z. Paál, P. Tétényi, J. Catal. 1977, 48, 442-444. (b) T. Szilágyi, A. Sárkány, J. Mink, P. Tétényi, J. Catal. 1980, 66, 191-199.

[8] D. J. Cole-Hamilton, R. P. Tooze, Catalyst Separation, Recovery and Recycling: Chemistry and Process Design, Springer, Dordrecht, Netherlands, 2006

[9] P. Barbaro, F. Liguori, Heterogenized Homogeneous Catalysts for Fine Chemicals Production: Materials and Processes, Springer, Dordrecht, Netherlands, 2010.

[10] A. Corma, H. Garcia, Eur. J. Inorg. Chem. 2004, 6, 1143-1164.

[11] M. Choi, Z. Wu, E. Iglesia, J. Am. Chem. Soc. 2010, 132, 9129-9137.

[12] I. Kuźniarska-Biernacka, O. Rodrigues, M. A. Carvalho, P. Parpot, K. Biernacki, A. L. Magalhães, A. M. Fonseca, I. C. Neves, Eur. J. Inorg. Chem. 2013, 2768-2776.

[13] N. Nunes, R. Amaro, F. Costa, E. Rombi, M. A. Carvalho, I. C. Neves, A. M. Fonseca, Eur. J. Inorg. Chem. 2007, 12, 1682-1689.

[14] I. Kuźniarska-Biernacka, K. Biernacki, A. L. Magalhães, A. M. Fonseca, I. C. Neves, J. Catal. 2011, 278, 102-110.

[15] P. Khemthong, W. Klysubun, S. Prayoonpokarach, J. Wittayakun, Mater. Chem. Phys. 2010, 121, 13个-137.

[16] K. C. Gupta, A. Kumar Sutar, C.-C. Lin, Coord. Chem. Rev. 2009, 253, 1926-1946.

[17] C. E. Song, S. Lee, Chem. Rev. 2002, 102, 3495-3524.

[18] P. Parpot, C. Teixeira, A. M. Almeida, C. Ribeiro, I. C. Neves, A. M. Fonseca, Microporous Mesoporous Mater. 2009, 117, 297-303. 
[19] K. K. Bania, R. C. Deka, J. Phys. Chem. C 2012, 116, 14295-14310.

[20] T. M. Salama, A. H. Ahmed, Z. M. El-Bahy, Microporous Mesoporous Mater. 2006, 89, 251-259.

[21] W. Lutz, C.H. Ruscher, D. Heidemann, Microporous Mesoporous Mater. 2002, 55, 193 202.

[22] G. F. Ghesti, J. L. de Macedo, V. C. I. Parente, J. A. Dias, S. C. L. Dias, Microporous Mesoporous Mater. 2007, 100, 27-34.

[23] I. Nakamura, N. Shiraiwa, R. Kanazawa, M. Terada, Org. Lett. 2010, 12, 4198-4200.

[24] H. Figueiredo, B. Silva, M. M. M. Raposo, A. M. Fonseca, I. C. Neves, C. Quintelas, T. Tavares, Microporous Mesoporous Mater. 2008, 109, 163-171.

[25] A. Vogt, S. Wołowiec, R. L. Prasad, A. Gupta, J. Skarżewski, Polyhedron 1998, 17, 1231 1240.

[26] (a) J. V. Bakboord, M. J. Cook, E. Hamuryudan, J. Porphyrins Phthalocyanines, 2000, 4, 510-517; (b) A. Yahay-Zadeh, Russ. J. Org. Chem. 2003, 39, 1649-1651.

[27] R. M. Silverstein, F. X. Webster, Spectrometric Identification of Organic Compounds, 6th ed. John Wiley \& Sons, Inc., New York, 1996.

[28] K. Nakamoto, Infrared and Raman Spectra in Inorganic and Coordination Compounds. Part II Application in Coordination, Organometallic and Bioinorganic Chemistry 5th ed. Willey, New York, 1997.

[29] S. Morin, P. Ayrault, N.S. Gnep, M. Guisnet, Appl. Catal. A 1998, 166, 281-292.

[30] K. Tanaka, C.-K. Choo, Y. Komatsu, K. Hamaguchi, M. Yamaki, T. Itoh, T. Nishigaya, R. Nakata, K. Morimoto, J. Phys. Chem. B 2004, P08, 2501-2508.

[31] C. Sedlmair, B. Gil, K. Seshan, A. Jentys, J. A. Lercher, Phys. Chem. Chem. Phys. 2003, 5, 1897-1905.

[32] B. Dutta, S. Jana, R. Bera, P.K. Saha, S. Koner, Appl. Catal. A 2007, 318, 89-94.

[33] P. J. Carl, S. Larsen, J. Phys. Chem. B 2000, 104, 6568-6575.

[34] S. Seelan, A. K. Sinha, Appl. Catal. A 2003, 238, 201-209.

[35] C. Teixeira, P. Pescarmona, M. A. Carvalho, A. M. Fonseca, I. C. Neves, New J. Chem. 2008, 32, 2263-2269.

[36] S. Seelan, A. K. Sinha, D. Srinivas, S. Sivasanker, J. Mol. Catal. A: Chem. 2000, 157, 163171 .

[37] B. Silva, H. Figueiredo, V. P. Santos, M. F. R. Pereira, J. L. Figueiredo, A. E. Lewandowska, M. A. Banãres, I. C. Neves, T. Tavares, J. Hazard. Mater. 2011, 192, 545553.

[38] (a) R. I. Kureshy, N. H. Khan, S. H. R. Abdi, I. Ahmad, S. Singh, R. V. Jasra, J. Catal. 2004, 22 1, 234-240; (b) Q.-H. Fan, Y.-M. Li, A. S. C. Chan, Chem. Rev. 2002, 102, 33853466 .

[39] K. Morokuma, J. Chem. Phys. 1971, 55, 1236-1244.

[40] K. Kitaura, K. Morokuma, Int. Quantum Chem. 1976, 10, 325-340.

[41] H. Umeyama, K. Morokuma, J. Am. Chem. Soc. 1977, 99, 1316-1332.

[42] R. G. Pearson, Proc. Natl. Acad. Sci. 1986, 83, 8440-8441.

[43] J. Taghavimoghaddam, G. P. Knowles, A. L. Chaffee, J. Mol. Catal. A: Chem. 2012, 358, 79-88.

[44] I. Kuźniarska-Biernacka, A. M. Fonseca, I. C. Neves, Inorg. Chim. Acta 2013, 394, 591597.

[45] M. Alizadeh , F. Farzaneh, M. Ghandi, J. Mol. Catal. A: Chem. 2003, 194, 283-287.

[46] M. L. Parentis, N. A. Bonini, E. E. Gonzo, React. Kinet. Catal. Lett. 2002, 76, 243-248.

[47] R. Jothiramalingam, B. Viswanathan, T. K. Varadarajan, J. Mol. Catal. A: Chem. 2006, 252, 49-55.

[48] X. Liu, C. M. Friend, Langmuir 2010, 26, 16552-16557.

[49] D. Duprez, F. Delanoë, J. Barbier Jr, P. Isnard, G. Blanchard, Catal. Today 1996, 29, 317322.

[50] E. A. Karakhanov, A. L. Maximov, Y. S. Kardasheva, V. A. Skorkin, S. V. Kardashev, E. A. Ivanova, E. Lurie-Luke, J. A. Seeley, S. L. Cron, Ind. Eng. Chem. Res. 2010, 49, 46074613.

[51] M. R. Maurya, S. J. J. Titinchi, S. Chand, Appl. Catal. A 2002, 228, 177-187. 
[52] M. R. Maurya, A. K. Chandrakar, S. Chand, J. Mol. Catal. A: Chem. 2007, 263, 227-237.

[53] M. R. Maurya, S. J. J. Titinchi, S. Chand, J. Mol. Catal. A: Chem. 2003, 193, 165-176.

[54] P. K. Saha, B. Dutta, S. Jana, R. Bera, S. Saha, K. Okamoto, S. Koner, Polyhedron 2007, 26, 563-571.

[55] B. P. Nethravathi, K. N. Mahendra, J. Porous Mat. 2010, 17, 107-113.

[56] T. H Bennur, D. Srinivas, P. Ratnasamy, Microporous Mesoporous Mater. 2001, 48, 111118 and ref. Herein.

[57] H. S. Abbo, S. J. J. Titinchi, Top. Catal. 2010, 53, 254-264.

[58] M. R. Maurya, C. Haldary, S. Behlz, N. Kamathamy, F. Avecilla, J. Coord. Chem. 2011, 64, 2995-3011.

[59] K. C. Gupta, A. K. Sutar, Polym. Adv. Technol. 2008, 19, 186-200.

[60] Y. Wu, L.-G. Qiu, W. Wang, Z.-Q. Li, T. Xu, Z.-Y. Wu, X. Jiang, Transition Met. Chem. 2009, 34, 263-268.

[61] M. R. Maurya, S. Sikarwar, J. Mol. Catal. A: Chem. 2007, 263, 175-185.

[62] I. A. Owsik, B. N. Kolarz, Catal. Today 2004, 91-92, 199-204.

[63] A. Jakubiak, I. A. Owsik, B. N. Kolarz, React. Funct. Polym. 2005, 65, 161-167.

[64] I. W. C. E. Arends, R. A. Sheldon, Appl. Catal. A 2001, 212, 175-187.

[65] M. J. Alves, B. L. Booth, A. P. Freitas, M. F. Proença, J. Chem. Soc., Perkin Trans 1 1992, 913-917.

[66] A. D. Becke, J. Chem. Phys. 1993, 98, 5648-5652.

[67] A. D. Becke, Phys. Rev. A 1988, 38, 3098-3100.

[68] C. Lee, W. Yang, R.G. Parr, Phys. Rev. B 1988, 37, 785-789.

[69] P. J. Stevens, F. J. Devlin, C. F. Chabalowski, M. J. Frisch, J. Phys. Chem. 1994, 98, 11623-11627.

[70] Gaussian 09, Revision A.1, M. J. Frisch, G. W. Trucks, H. B. Schlegel, G. E. Scuseria, M. A. Robb, J. R. Cheeseman, G. Scalmani, V. Barone, B. Mennucci, G. A. Petersson, H. Nakatsuji, M. Caricato, X. Li, H. P. Hratchian, A. F. Izmaylov, J. Bloino, G. Zheng, J. L. Sonnenberg, M. Hada, M. Ehara, K. Toyota, R. Fukuda, J. Hasegawa, M. Ishida, T. Nakajima, Y. Honda, O. Kitao, H. Nakai, T. Vreven, J. A. Montgomery, Jr., J. E. Peralta, F. Ogliaro, M. Bearpark, J. J. Heyd, E. Brothers, K. N. Kudin, V. N. Staroverov, R. Kobayashi, J. Normand, K. Raghavachari, A. Rendell, J. C. Burant, S. S. Iyengar, J. Tomasi, M. Cossi, N. Rega, J. M. Millam, M. Klene, J. E. Knox, J. B. Cross, V. Bakken, C. Adamo, J. Jaramillo, R. Gomperts, R. E. Stratmann, O. Yazyev, A. J. Austin, R. Cammi, C. Pomelli, J. W. Ochterski, R. L. Martin, K. Morokuma, V.. G. Zakrzewski, G. A. Voth, P. Salvador, J. J. Dannenberg, S. Dapprich, A. D. Daniels, Ö. Farkas, J. B. Foresman, J. V. Ortiz, J. Cioslowski, and D. J. Fox, Gaussian, Inc., Wallingford CT, 2009.

[71] P. Flükiger, H.P. Lüthi, S. Portmann, J. Weber, MOLEKEL 4.3: Molecular Visualization Software, Swiss Center for Scientific Computing, Manno, Switzerland, 2000.

[72] GaussView, Version 5, R. Dennington, T. Keith, J. Millam, Semichem Inc., Shawnee Mission KS, 2009. 